\title{
HACIA UNA CONCEPCIÓN SUSTANTIVA \\ DEL IUS POST BELLUM: \\ UN ARGUMENTO HOBBESIANO'
}

\section{Towards a substantive conception of ius post bellum: a Hobbesian argument}

\author{
RICARDO GARCÍA MANRIQUE \\ Universidad de Barcelona \\ garcia.manrique@ub.edu
}

Cómo citar/Citation

García Manrique, R. (2018).

Hacia una concepción sustantiva del ius post bellum: un argumento hobbesiano. Revista de Estudios Políticos, 182, 251-269. doi: https://doi.org/10.18042/cepc/rep. 182.09

\section{Resumen}

La teoría del contrato social, en su versión hobbesiana, puede ser una base adecuada para justificar una concepción sustantiva del ius post bellum. El ius post bellum puede entonces caracterizarse como una renovación del contrato social en la que el elemento instaurativo ha de primar sobre el restaurativo y el transicional. Esta concepción descansa sobre dos presupuestos: que solo una paz orientada dinámicamente hacia la justicia puede ser estable y sólida; y que el tiempo de la justicia es el futuro más que el pasado. En consecuencia, el ius post bellum debería contener, al menos, el reconocimiento del derecho al mínimo vital, que puede apoyarse tanto en la lectura de la obra de Hobbes como en una serie de recientes decisiones de diversas jurisdicciones nacionales e internacionales.

1 Este trabajo forma parte de los resultados del proyecto de investigación El Ius Post Bellum como Herramienta de Construcción de Paz y de Promoción de una Justicia Transformativa, financiado por el Institut Català Internacional per la Pau (ref. 2016RICIP00005). 


\section{Palabras clave}

Ius post bellum; contrato social; Hobbes; derecho al mínimo vital.

\section{Abstract}

The social contract theory, in the Hobbesian version, could be a suitable foundation for the justification of a substantive conception of ius post bellum. Ius post bellum might thus be characterized as a renewal of the social contract in which the instaurative element prevails over the restaurative and the transitional ones. This conception rests on two assuptions: the first one is that peace will be solid and stable only when it is dynamically orientated towards justice; the second one is that the time of justice is always the future and not the past. As a consequence, ius post bellum should include, at least, the right to a minimum standard of living, a right that can be supported on a certain reading of Hobbes' works as well as on a series of rulings issued by a variety of domestic and international courts.

\section{Keywords}

Ius post bellum; social contract; Hobbes; right to a minimum standard of living. 


\section{SUMARIO}

I. HOBBES Y EL IUS POST BELLUM: EL PORQUÉ DE UNA AUSENCIA. II. DOS CONCEPCIONES DEL IUS POST BELLUM: LA VIGENCIA DEL LEVIATÁN. III. EL DERECHO AL MÍNIMO VITAL COMO CONTENIDO DEL IUS POST BELLUM. BIBLIOGRAFIA.

\section{HOBBES Y EL IUS POST BELLUM: EL PORQUÉ DE UNA AUSENCIA}

Cuando la literatura académica dedicada al ius post bellum se ocupa de rastrear sus orígenes históricos en la filosofía jurídico-política moderna, uno se encuentra con la sorpresa de que la teoría de Hobbes no figura entre ellos. En cambio, se menciona a Vitoria y a Suárez como precedentes, desde luego a Hugo Grocio y su De Iure Belli ac Pacis, a iusnaturalistas como Wolff y Vattel y, en fin, al Kant de La paz perpetua (Orend, 2000: 118; Stahn, 2007a: 921; Stahn, 2007b: 313-314; Sharma, 2008: 13-17; Orend, 2008: 34-35; De Brabandere, 2014: 127). Qué sea o haya de ser exactamente el ius post bellum es asunto sujeto a controversia, tanto mayor cuanto que se trata de un sector del derecho internacional aún no consolidado, ni siquiera en el nivel doctrinal. A los efectos de este estudio, entenderemos por ius post bellum el «cuerpo de normas jurídicas que se aplica al proceso de transición desde un conflicto armado hacia una paz justa y sostenible» (Iverson, 2014: 85).

La ausencia de Hobbes en este panorama llama la atención si tenemos en cuenta que su teoría política contiene, ante todo, una propuesta para abandonar el estado de guerra y entrar en un estado de paz, y esto tanto en un sentido genérico o abstracto como en otro mucho más concreto. En un sentido genérico, porque Hobbes, como buen contractualista, contrapone el estado civil al estado de naturaleza, pero caracteriza a este como un "estado de guerra» (la famosa bellum omnium contra omnes del capítulo XIII del Leviatán), a diferencia del modo mucho más amable en que años después lo describirá Locke en su Ensayo sobre el gobierno civil (Locke, 2010 [1690], caps. 2 y 9). Es decir, el contrato social hobbesiano es un instrumento concebido para acabar con la guerra e inaugurar la era de la paz. Además, en un sentido mucho más concreto, Hobbes publica su Leviatán en $1651^{2}$, en el

2 La versión inglesa del De Cive apareció en ese mismo año. Para lo que aquí interesa, bastará apoyarse en la lectura del Leviatán, porque el De Cive no contiene variaciones significativas al respecto. 
contexto de la guerra civil inglesa y con el propósito declarado de contribuir a resolverla (se trata de un libro, escribe en su último párrafo, «occasioned by the disorders of the present time»; Leviathan, "A Review and Conclusion», 445$)^{3}$.

Que Hobbes haya sido excluido de los precursores del ius post bellum puede deberse a dos motivos, uno más evidente y otro no tanto. El más evidente es que el ius post bellum contemporáneo se concibe como parte de un más genérico «derecho de guerra», que estaría compuesto por el ius ad bello, el ius in bello y el propio ius post bellum, los dos primeros de más larga tradición y el tercero, su dimensión más reciente, todavía en trance de constitución doctrinal y normativa y prácticamente desconocido hace unas cuantas décadas (Iverson, 2014: 80). Este derecho de guerra y sus tres partes serían a su vez el correlato jurídico de una "teoría de la guerra justa» y de los tres momentos de toda guerra: inicio, desarrollo y desenlace (Bass, 2004: 385; Orend, 2008). Sin embargo, es cierto que no encontraremos en la obra de Hobbes una teoría de la guerra justa porque «guerra» $\mathrm{y}$ «justicia» son, a su parecer, términos antitéticos: no puede haber justicia, ni derecho, salvo en la paz, y esto es lo que, en última instancia, justifica la paz y las instituciones políticas que la garantizan: el hecho de que la paz sea condición necesaria de la justicia. Por eso, la concepción hobbesiana de la guerra se aleja de la tradición de la doctrina de la guerra justa, y por eso, Hobbes queda excluido de los precedentes del ius post bellum.

El motivo menos evidente es el vínculo que tiende a establecerse entre la teoría política de Hobbes y la legitimación del absolutismo. En sus versiones más toscas, este vínculo llegaría a ser incluso una definición o una identificación: la teoría política de Hobbes no sería otra cosa que un intento de justificar ese particular régimen. En otras versiones más matizadas, la teoría de Hobbes, si no como objeto central, sí tendría como consecuencia principal la legitimación de esa forma no democrática del poder político. En un caso y en el otro, «la impresión común de Hobbes es la de un teórico del poder político absoluto» (Tuck, 1989: 69). Siendo así, el Leviatán (a diferencia, por ejemplo, de La paz perpetua kantiana) habría perdido su interés para un tiempo como el nuestro, donde el absolutismo ya no es una opción a considerar. Por eso, una teoría del ius post bellum no puede contar con quien no era sino el defensor de una forma caduca de articulación de lo político.

Ambos motivos son cuestionables. El primero porque la construcción de un ius post bellum como parte de una teoría de la guerra justa no es la única

3 Cito por la edición de la MacMaster University disponible en la Red. Las traducciones que figuran a pie de página pertenecen a la versión española de Carlos Mellizo (Hobbes, 1999 [1651]). 
posible, incluso puede que no sea la más recomendable. Este será el caso para quienes crean que no hay guerras justas, acaso con el argumento de que generan dilemas morales irresolubles en términos de justicia, que nos obligan a elegir entre cursos de acción igualmente injustos (Nagel, 1972: 143-144; Walzer, 1977: 326-327; Ruiz Miguel, 1988: 308), o con el argumento de que toda guerra contemporánea supone la muerte de personas inocentes, y la muerte de personas inocentes no puede ser justa en ningún caso (García Manrique, 2008: 133-135). En otros términos, en la guerra no se darían las que Rawls llama "circunstancias de la justicia», esto es, aquellas circunstancias en las que no es posible valorar los comportamientos propios o ajenos como justos o injustos, porque están ausentes las condiciones en las cuales la cooperación humana es tanto posible como necesaria (Rawls, 1973: 126-127)

Si no hay guerras justas, entonces no puede haber una teoría de la guerra justa, ni tiene sentido entonces configurar un ius post bellum como parte de una teoría tal. Por otra parte, la opción por un ius post bellum que no se apoye en una teoría de la guerra justa puede ser también la de quienes creen que los contenidos principales del ius post bellum no deben depender de la justicia o injusticia de la guerra precedente, esto es, que el ius post bellum ha de ser autónomo respecto del ius ad bellum y del ius in bello, y que ha de mantener la vista puesta en el futuro más que en el pasado (Stahn, 2008: 233-234). Para todos ellos, las disquisiciones hobbesianas pueden resultar interesantes, como veremos.

En cuanto al segundo motivo, está basado en un error que conviene rectificar. Hobbes no es solo, ni principalmente, un teórico del absolutismo, sino de la comunidad política legítima, sea absolutista o no. Es cierto que, en el contexto que le tocó vivir (el de la guerra civil inglesa), pareció optar por el absolutismo como el régimen que mejor podía solucionar el que considera problema central de la legitimidad política, que es el de la paz. Sin embargo, su teoría del contrato social no es, ni mucho menos, una teoría que aboque necesariamente al absolutismo. Al contrario, en cuanto que teoría contractualista, es una teoría de raíz democrática con la que se produce la que Bobbio llamó «inversión de la relación política», de manera que, a partir del «modelo hobbesiano» el poder político se legitima desde abajo hacia arriba (esto es, democráticamente) y no

4 Por eso sorprende que el propio Rawls, en otro lugar, sostenga que una guerra puede seguir siendo justa aun cuando las circunstancias en las que tiene lugar sean tan excepcionales como para dejar de lado el estatuto que protege a la población civil de todo ataque militar (Rawls, 2001: 117). La idea de las circunstancias de la justicia, por cierto, la toma Rawls de Hume, quien sobre la guerra escribió, con la que juzgo como mayor coherencia: «The rage and violence of public war: what is it but a suspension of justice among the warring parties, who perceive that this virtue is now no longer of any use or advantage to them?» (Hume 1983 [1751]: 23). 
viceversa (Bobbio, 1985: 171 y ss.). Las palabras del propio Hobbes no dejan lugar a dudas cuando define el contrato social en estos términos:

This is more than consent, or concord; it is a real unity of them all in one and the same person, made by covenant of every man with every man, in such manner as if every man should say to every man: I authorise and give up my right of governing myself to this man, or to this assembly of men, on this condition; that thou give up, thy right to him, and authorise all his actions in like manner. This done, the multitude so united in one person is called a Commonwealth; in Latin, Civitas (Leviathan, XIII: 106; las cursivas son mías y resaltan el sentido democrático del Leviatán hobbesiano) $)^{5}$.

Este fundamento democrático del Leviatán hobbesiano es lo que importa, y no tanto que, bajo determinadas circunstancias, que pueden cambiar, el absolutismo político sea la mejor expresión institucional de ese fundamento, en tanto que más adecuada para garantizar el fin último de lo político, a saber, la conservación de la vida de los ciudadanos a través de la paz. Sobre el sentido y alcance de este fin volveremos más adelante, pero su mera formulación basta para observar que, como lo dijo Meinecke, «el Leviatán no tiene alma propia» (Meinecke, 1983: 218), puesto que su alma es la de los ciudadanos, como, en realidad, lo es en cualquier modelo que podamos calificar como contractualista, en el que el Estado es siempre medio y nunca fin (Fernández, 1987: 145 y ss.).

Si esto es así, entonces el segundo motivo que justificaría la exclusión de Hobbes de entre los precursores del ius post bellum también lo podemos rechazar. Ni el ius post bellum ha de ser concebido necesariamente como parte de una más amplia teoría de la guerra justa ni la propuesta política hobbesiana es necesariamente absolutista. ¿Qué nos queda entonces? Una teoría política muy sólida cuyo fin último es precisamente el establecimiento de una paz estable sobre una base democrática, a partir de una situación previa caracterizada como «guerra». Una teoría que, por tanto, puede ser útil para quienes se interesan por el ius post bellum.

5 «Algo más que consentimiento o concordia; es una verdadera unidad de todos en una y la misma persona, unidad a la que se llega mediante un acuerdo de cada hombre con cada hombre, como si cada uno estuviera diciendo al otro: autorizo y concedo el derecho de gobernarme a mí mismo, dando esa autoridad a este hombre o a esta asamblea de hombres, con la condición de que tú también le concedas tu propio derecho de igual manera, y le des esa autoridad en todas sus acciones. Una vez hecho esto, una multitud así unida en una persona es lo que llamamos República, en latín Civitas». 


\section{DOS CONCEPCIONES DEL IUS POST BELLUM: LA VIGENCIA DEL LEVIATÁN}

Un rápido y somero examen de la literatura académica al respecto muestra que hay dos concepciones dominantes del ius post bellum, que podemos llamar «restaurativa»e "instaurativa» y que aquí se presentan solo con una intención instrumental, de cara a facilitar la exposición de lo que sigue. Haciendo abstracción de las diferencias y de los matices (que ciertamente son muchos), la concepción restaurativa del ius post bellum se caracteriza por su intención de restaurar (recuperar, rehabilitar) una situación pasada (social, política, jurídica) que el conflicto bélico habría alterado. De aquí se siguen estos caracteres: 1) el ius post bellum es procedimental, es decir, no tiene contenidos sustantivos propios, puesto que su intención es articular un procedimiento que permita volver a una situación preexistente; 2) el ius post bellum tiene una vigencia temporal o provisional, puesto que, una vez recuperada la situación preexistente (o, si se quiere, la que venga dictada por principios sustantivos en todo caso ajenos al ius post bellum), pierde su razón de ser; 3) el ius post bellum prioriza los aspectos correctivo y retributivo de la justicia, puesto que pretende corregir las desigualdades generadas por la guerra (aquí las desigualdades son entendidas como alteraciones de un orden previamente existente y considerado justo; pueden ser de muchos tipos, claro está), y compensar (es decir, retribuir) ciertas acciones que han tenido lugar durante la guerra, y por eso, 4) el ius post bellum habilita en su seno un lugar prioritario a la justicia transicional, o incluso podemos decir que el ius post bellum restaurativo no es sino el derecho de la justicia transicional.

Por el contrario, de acuerdo con la concepción instaurativa, el objetivo del ius post bellum es establecer ciertas condiciones que aseguren la paz, con independencia de las que existieran antes del conflicto bélico (e incluso en oposición con ellas, puesto que esas condiciones preexistentes suelen ser valoradas como las causantes más o menos directas del conflicto). De aquí se siguen unos caracteres definitorios del ius post bellum que son los opuestos a los de la concepción restaurativa: 1) el ius post bellum no es solo ni principalmente procedimental, sino que incluye contenidos sustantivos, aquellos que pueden asegurar la paz; 2) el ius post bellum tiene vocación de permanencia, puesto que la paz requiere que los contenidos del ius post bellum se mantengan; 3) el ius post bellum prioriza el aspecto distributivo de la justicia frente al correctivo y el retributivo, en tanto que la justicia distributiva es la modalidad de la justicia según la cual se asignan las cargas y los beneficios ciudadanos que definen sustantivamente una comunidad, y 4) el ius post bellum, en fin, puede contener normas de justicia transicional, pero no les asigna un lugar central, ni mucho menos exclusivo. 
Por supuesto, estas dos concepciones son ideales (y por eso he preferido no asociarlas con autores determinados), en el sentido de que no tratan de reflejar propuestas concretas, en las que, en cambio, lo que encontraremos son distintas combinaciones que toman elementos de una y de otra. Por poner un par de ejemplos, hay quien sostiene que el ius post bellum es «a law of transition by definition", pero al tiempo admite que no cabe entenderlo como orientado al retorno a una situación anterior y que debe promover un alto nivel de garantía de los derechos humanos (Stahn, 2007b: 310-311). Y hay quien observa, en línea con esta última afirmación, que las diferencias entre unas y otras concepciones del ius post bellum no afectan a la idea de que los derechos humanos han de ser un componente necesario de toda concepción posible, con independencia del carácter más o menos transicional que se le quiera atribuir (Österdahl, 2012: 281 y 285).

No es este el lugar apropiado para evaluar con detalle cuál de las dos concepciones del ius post bellum es preferible. Me limitaré, por tanto, a optar por la segunda con base en dos razones (provisionales, si se quiere, y acaso necesitadas de apoyo empírico):

1) La mayor parte de las guerras contemporáneas tiene lugar en países o regiones cuya situación política, económica y social puede calificarse como mala o muy mala. Por eso, la idea de volver a la situación anterior a la guerra no parece muy recomendable. Además, es muy posible que esa situación previa haya sido una de las causas (o la causa principal) de la guerra.

2) Los desastres de la guerra contemporánea suponen un alto nivel de destrucción de estructuras comunitarias básicas (políticas, administrativas, productivas, comerciales, de comunicación, sanitarias, educativas...). Haciendo de la necesidad virtud, el momento de reconstruir lo preexistente puede convertirse en el momento de construir algo nuevo y mejor sobre bases más eficaces y justas.

Un ius post bellum instaurativo me parece, pues, más deseable y más acorde con la tendencia del derecho internacional contemporáneo a vincular los procesos de paz con el establecimiento y aseguramiento de un determinado modelo político y jurídico: el de la democracia constitucional. Por una parte, esta concepción responde al concepto genérico del ius post bellum (recuérdese la definición de Iverson antes citada; otra muy semejante es la de Kleffner, para quien el ius post bellum ha de identificarse siempre como el intento de dar respuesta a la pregunta «how to move from armed conflict to a durable peace»; Kleffner, 2008: 1). Por otra parte, responde a la orientación particular de quienes atribuyen contenidos sustantivos insoslayables al ius post bellum: en este sentido, los derechos 
humanos parecen el candidato con más posibilidades (Wilde, 2008), una reivindicación (la de los derechos) que vale también para quienes sostienen una concepción del ius post bellum basada en la teoría de la guerra justa, y sobre la asunción de que la guerra (justa) se ha originado en la violación de algunos de estos derechos; de manera que «vindicating rights, not vindictive revenge, is the order of the day» (Orend, 2008: 40).

Pues bien, una concepción instaurativa del ius post bellum puede encontrar inspiración en las ideas de Thomas Hobbes. Ante todo, porque una concepción de este tipo atribuye tres problemas centrales al ius post bellum: el de la soberanía, el del imperio de la ley y el de la justicia distributiva (Pugh, 2008), que son justamente los tres elementos centrales de la teoría política de Hobbes. Más allá de este vínculo general, hay cuatro razones más concretas, relacionadas todas ellas con la idea misma de la paz, que habrían de despertar el interés de los partidarios de un ius post bellum no meramente transicional y sí dotado un de contenido sustantivo: 1) la de Hobbes es una de las doctrinas políticas que mayor preeminencia atribuyen al ideal de la paz; 2) la paz hobbesiana es una paz instaurada y no restaurada; 3) esta paz está basada en contenidos materiales, y 4) se trata de contenidos materiales mínimos que permiten una aceptación generalizada, como veremos a continuación.

Por todo ello, cabe añadir ahora, quienes se muestran partidarios de un concepto "positivo» de paz, esto es, una paz definida no como la negación de la guerra sino a través de rasgos afirmativos (Stahn, 2007b: 323; Gready y Robins, 2014: 350; Calvet y Díaz Anabitarte, 2018), habrán de ver también con buenos ojos la propuesta hobbesiana, que consiste precisamente en una compleja articulación de la comunidad política pacífica, esto es, en una descripción positiva de la paz, hasta el punto de que, a diferencia de lo que suele ser más habitual, en su obra es la guerra la que aparece definida en negativo como la ausencia de paz (puesto que, para Hobbes, toda situación en la cual fallen los elementos constitutivos del contrato social es una situación de guerra, actual o potencial; y puesto que su principal afán consiste en la descripción, y por supuesto prescripción, de tales elementos constitutivos).

\section{EL DERECHO AL MÍNIMO VITAL COMO CONTENIDO DEL IUS POST BELLUM}

En lo que sigue, voy a sugerir que la garantía de un mínimo vital ha de ser un contenido necesario de todo ius post bellum concebido a la manera instaurativa que acaba de ser identificada, y lo voy a hacer apoyándome en un argumento extraído del Leviatán. Si estoy en lo cierto, esto habría de mostrar que la fecundidad de las ideas del viejo filósofo inglés está lejos de agotarse; 
pero sobre todo, habría de constituir una buena razón para que quienes se ocupan del ius post bellum asuman la garantía del mínimo vital entre sus contenidos innegociables. El argumento hobbesiano lo complementaré con la referencia a una serie de decisiones relativamente recientes de tribunales nacionales e internacionales que han reconocido igualmente alguna variante del derecho al mínimo vital. No se trata de decisiones vinculadas con procesos de transición de la guerra a la paz; sin embargo, sus fundamentos jurídicos son análogos a la manera de razonar de Hobbes y creo que pueden extenderse también al ámbito del ius post bellum.

Quienes sostienen que la teoría política de Hobbes es una teoría absolutista no se apoyan solo en el hecho ya reseñado de que Hobbes favoreciese la solución absolutista como la más apropiada para acabar con la guerra civil inglesa; también lo hacen en su defensa de la obediencia absoluta que el ciudadano debe al soberano. Esta obediencia absoluta sería exigida por la necesidad de mantener la vigencia de la paz. Así, a cambio de su obediencia incondicional al soberano y a sus mandatos (a su derecho), el ciudadano obtendría esa paz, supuestamente mejor que la guerra, pero una paz desnuda, esto es, una paz compatible con cualesquiera mandatos del soberano, con su poder omnímodo.

Una teoría de la legitimidad política como esta sería, desde luego, muy poco atractiva y muy poco convincente, pues ¿qué razones tendrían los individuos para someterse a una autoridad que no les garantizase nada? ¿Acaso una paz vacía de todo contenido material puede ser en algún sentido mejor que la guerra que es propia del estado de naturaleza? ¿Es siquiera concebible, conceptualmente posible, esa paz? Si esta fuera la paz que ofrece el Leviatán, llevaría mucha razón Habermas cuando señala que Hobbes se ve envuelto en una "contradicción realizativa», puesto que, por una parte, su teoría trata de explicar cómo el derecho "funciona de forma ajena a toda moral» (esto es, podría contener cualesquiera contenidos, por inmorales que fueran, $y$, por tanto, podría no garantizar interés alguno de los ciudadanos); pero, por otra parte, trata de convencer a sus lectores de "por qué podrían tener buenas razones como ciudadanos libres e iguales para decidir someterse a un poder estatal absoluto»; de este modo, el "contenido manifiesto de su teoría» sería contradictorio con «el papel pragmático de la teoría misma» (Habermas, 1998: 579).

A una conclusión semejante parece llegar Bobbio cuando observa que el discurso hobbesiano acerca del derecho natural (vale decir: la moral) acaba por reducirse a la obligación de obedecer el derecho positivo (Bobbio, 1985: 159); es semejante porque resultaría que el soberano no estaría limitado, a la hora de dictar normas positivas, por normas sustantivas (dado que el derecho natural, siempre según Bobbio, se limitaría a ese único mandato que 
requiere obediencia al derecho positivo). De esta manera, al ciudadano se le exigiría una obediencia que no tendría correlato en obligación alguna del soberano, lo cual, en efecto, tiene todo el aspecto de ser contradictorio. Un pasaje que sea explícito en este sentido no se encuentra en el Leviatán, aunque sí en el De Cive:

Al ser la obligación de observar esas leyes [civiles] anterior a su promulgación, por estar contenida en la propia constitución del estado, en virtud de la ley natural que prohíbe violar los pactos, la ley natural ordena observar todas las leyes civiles. Porque cuando nos obligamos a obedecer antes de saber qué se va a mandar, nos obligamos a obedecer de forma general y en todo (Hobbes, 1993 [1642]: XIV-10, 122-123; las cursivas son mías).

No cabe duda de que la afirmación de una obligación absoluta de obediencia al poder establecido resulta paradójica en el seno de una teoría de la legitimidad política y le resta mucho de su atractivo. Sin embargo, como veremos a continuación, hay pasajes en la obra de Hobbes donde esta obligación no está caracterizada como absoluta, sino que admite excepciones relevantes. A mi parecer, estos pasajes son más consistentes con el resto de su obra que aquellos otros (como el que acaba de ser citado) en los que parece no haber lugar alguno para la desobediencia. Por eso, lo que sí podrá afirmarse es que la obra de Hobbes no es coherente en este punto o, por lo menos, no es lo suficientemente clara. Sin embargo, la cuestión de la obediencia es distinta de la cuestión de los fines del Estado; esto es, una cosa es determinar los supuestos en los que cabe la desobediencia justificada y otra cosa es establecer cuáles son los fines sustantivos que deben guiar la acción de gobierno, de manera que estos fines siguen determinando su legitimidad incluso aunque no quepa la desobediencia como respuesta a su desconocimiento (por otra parte, nada sorprendente, pues ninguna teoría de la desobediencia civil permite justificarla con el mero incumplimiento por parte del Gobierno de uno cualquiera de sus fines). Por eso, incluso si Hobbes postulara una obediencia absoluta (o, como prefiero interpretar, una obediencia con excepciones), de aquí no se sigue que el derecho funcione de manera ajena a toda moral (Habermas) ni tampoco que el único contenido del derecho natural hobbesiano sea la obligación de obedecer el derecho positivo, o que ese derecho natural sea solo el fundamento formal de la validez del derecho positivo (Bobbio). Por el contrario, la de Hobbes sigue siendo una teoría basada en fines sustantivos que preceden al derecho positivo, fines cuya satisfacción es la que legitima el origen y el ejercicio de las instituciones políticas (Warrender, 1957: 322 y ss.; Neumann, 1986: 103; Murphy, 1995). 
Pero vayamos a los textos para comprobar que, en efecto, la paz hobbesiana, la que garantiza el Leviatán, tiene un contenido sustantivo, cuyo mínimo ha de ser respetado por este si pretende obediencia del ciudadano. A la hora de definir los límites de esta obediencia, Hobbes escribe: "The obligation of subjects to the sovereign is understood to last as long, and no longer, than the power lasteth by which he is able to protect them. For the right men have by nature to protect themselves, when none else can protect them, can by no covenant be relinquished» (Leviathan, XXI: 136) ${ }^{6}$.

Luego, por tanto, el correlato de la obediencia del ciudadano es la protección que les brinda el soberano. ¿La protección de qué? Al menos, de la vida. Por eso resulta: «If the sovereign command a man, though justly condemned, to kill, wound, or maim himself; or not to resist those that assault him; or to abstain from the use of food, air, medicine, or any other thing without which he cannot live; yet hath that man the liberty to disobey» (Leviathan, XXI: $134)^{7}$.

Ahora bien, la «vida» no ha de entenderse como mera preservación, sino: «The office of the sovereign [...] consisteth in the end for which he was trusted with the sovereign power, namely the procuration of the safety of the people [...]. But by safety here is not meant a bare preservation, but also all other contentments of life, which every man by lawful industry, without danger or hurt to the Commonwealth, shall acquire to himself» (Leviathan, XXX: 205; las cursivas son mías) $)^{8}$.

Es más, a esta «vida» que no es "mera preservación» no costaría mucho añadir un cierto grado de libertad, con apoyo en pasajes como este: "The liberty of a subject lieth therefore only in those things which, in regulating their actions, the sovereign hath pretermitted: such as is the liberty to buy, and sell, and otherwise contract with one another; to choose their own abode, their

6 «La obligación de los súbditos para con el soberano se sobreentiende que durará lo que dure el poder de éste para protegerlos, y no más. Pues el derecho que por naturaleza tienen los hombres para protegerse a sí mismos cuando nadie más puede protegerlos, es un derecho al que no puede renunciarse mediante convenio alguno".

7 «Si el soberano manda a un hombre (aunque este haya sido condenado justamente) a que se mate, se hiera o se mutile a sí mismo, o que no haga resistencia a quienes lo asaltan, o que se abstenga de hacer uso de comida, aire, medicina o cualquier otra cosa sin la cual no podrá vivir, ese hombre tendrá la libertad de desobedecer».

8 «La función del soberano [...] consiste en el fin para el cual fue investido con el poder soberano, a saber, procurar la seguridad del pueblo [...]. Pero por seguridad no debe aquí entenderse una mera preservación, sino también todas las demás satisfacciones de la vida que cada hombre, mediante su legítimo trabajo, y sin peligro o daño para el estado, adquiera para sí». 
own diet, their own trade of life, and institute their children as they themselves think fit; and the like» (Leviathan, XXI: 131)

Cierto es que esta relativamente amplia libertad a la que se refiere Hobbes aparece aquí como "ejemplo». Sin embargo, hay quien, con apoyo en este párrafo, y creo que con buen criterio, ha interpretado que Hobbes «exige una esfera de libertad económica y cultural para el ciudadano individual» (Neumann, 1986: 107). Tampoco la igualdad entre los ciudadanos está ausente del Leviatán: en su capítulo XXX (dedicado a la "función del representante soberano») encontramos numerosas alusiones al contenido mínimo que esa igualdad ha de tener. Allí, como obligaciones del Estado, figuran la de cuidar de que «la justicia sea igualmente administrada en todos los estratos del pueblo»; la de establecer una «igualitaria aplicación de impuestos»; e incluso la de proveer a todos los que son incapaces de mantenerse a sí mismos «en todo aquello que es requerido por las necesidades naturales». Conviene citar literalmente de nuevo en relación con esta última obligación pública, de marcado carácter asistencial: "And whereas many men, by accident inevitable, become unable to maintain themselves by their labour, they ought not to be left to the charity of private persons, but to be provided for, as far forth as the necessities of nature require, by the laws of the Commonwealth» (Leviathan, XXX: 213).

Por supuesto, el Estado tiene otras funciones además de estas, pero hago hincapié en aquellas que demuestran lo que importa retener ahora, esto es, que el Estado nacido del contrato social es un Estado que tiene fines predeterminados, que estos son sustantivos, y que constituyen las razones de la legitimidad política y del correlativo deber ciudadano de obediencia al derecho. La paz hobbesiana no es, ni mucho menos, cualquier paz, sino precisamente una que es claramente preferible a la guerra porque es una paz lo suficientemente justa: justicia y paz van de la mano en el Leviatán.

Este mínimo de justicia que la autoridad política debe garantizar para ser considerada legítima (y, en particular, esa obligación asistencial del Estado que aparece en el último pasaje citado de Hobbes) recuerda mucho, dando un salto en el tiempo hasta nuestros días, a ciertos modos de argumentar de algunos tribunales superiores que, en los últimos años, han reconocido con esa misma base un derecho al mínimo vital, esto es, a la satisfacción de ciertas necesidades materiales mínimas, entre las que hay que contar por lo menos el

9 «La libertad de un súbdito radica, por tanto, solamente, en aquellas cosas que en la regulación de sus acciones ha pretermitido el soberano: por ejemplo, la libertad de comprar y vender y de hacer, entre sí, contratos de otro género, de escoger su propia residencia, su propio alimento, su propio género de vida, e instruir a sus niños como crea conveniente, etc.». 
agua, la alimentación y la vivienda. Es el caso de la Corte Constitucional colombiana, que ya en 1992 (sentencia Cifuentes Muñoz) consideró el derecho al mínimo vital como un derecho subjetivo de aplicación inmediata cuando la persona se encuentra en estado de debilidad manifiesta y se prueba la incapacidad material de la familia para asistirla. La Corte considero que un tal derecho es un «núcleo esencial mínimo, no negociable en el debate democrático» (Champeil-Desplats, 2012: 229). Es también el caso del Tribunal Federal suizo, que en 1995 reconoció un derecho equivalente como derecho subjetivo de todos los ciudadanos, considerado como la "condición de ejercicio de todos los demás derechos fundamentales» (poco tiempo después, en 1999, la Constitución suiza incorporó este derecho en su art. 12, esto es, el derecho a «recibir los medios indispensables para mantener una existencia conforme con la dignidad humana»). En años subsiguientes, otros tribunales superiores han reconocido derechos muy similares. Así lo han hecho los Tribunales Supremos de India, Israel y Sudáfrica, y el Tribunal Constitucional alemán (Fercot, 2012).

Esta tendencia jurisprudencial hacia el reconocimiento de un derecho al mínimo vital tiene también una moderada pero inequívoca expresión en el ámbito del derecho internacional regional. Así, en 2002, el Tribunal Europeo de Derechos Humanos se expresaba en estos términos: «The Court considers that a complaint about a wholly insufficient amount of pension and the other social benefits may, in principle, raise an issue under Article 3 of the Convention which prohibits inhuman or degrading treatment» (Larioshina c. Rusia, 23 de abril de 2002, decisión de inadmisión; esta consideración se reiteró en Budina c. Rusia, 18 de junio de 2009, decisión de inadmisión).

Cierto es que, en ambos casos, el Tribunal de Estrasburgo decidió no admitir la demanda, porque juzgó que los medios de que disponía la demandante la situaban por encima del umbral de pobreza que marca el límite del trato inhumano o degradante; pero lo que importa es que el Tribunal aceptó que, si la pobreza es realmente extrema, podemos estar ante una situación prohibida por la Convención, que los Estados, por tanto, tienen la obligación de remediar (López Guerra, 2015: 404-405; Mestre, 2016: 116). En cambio, hay quien, atendiendo a otras decisiones sobre asuntos semejantes, se muestra más cauteloso sobre la posibilidad de que el Tribunal europeo llegue a establecer un derecho al mínimo vital (Nivard, 2012: 518 y ss.). Sea como sea, si se animara a hacerlo, contaría con el apoyo del propio Comité de Ministros del Consejo de Europa, que, en su Recomendación R-2000 3, exhortó a los Estados miembros a garantizar por vías jurisdiccionales un derecho a la satisfacción de las necesidades elementales de las personas en situación de extrema precariedad. 
Por su parte, la Corte Interamericana de Derechos Humanos, hasta donde sé, no ha realizado todavía un pronunciamiento similar; no obstante, su jurisprudencia contiene ya elementos suficientes para poder llevarlo a cabo sin gran esfuerzo argumentativo adicional. Por una parte, porque en alguna ocasión ha establecido un vínculo entre el respeto al derecho la «integridad personal» y la satisfacción de ciertos niveles mínimos de asistencia sanitaria (así, en la sentencia Alban Cornejo vs. Ecuador, de 2007). Por otra parte, porque las sentencias Yvon Neptune vs. Haití, de 2008, y Pacheco Teruel y otros vs. Honduras, de 2012, que reconocen el derecho de las personas privadas de libertad a ciertos niveles de bienestar material, constituirían una buena base para extender ese derecho al resto de los ciudadanos, teniendo en cuenta que ese derecho no lo funda la Corte de San José de manera prioritaria en la condición de reclusos de sus titulares. Es posible además que, por la vía de la justiciabilidad directa de los derechos sociales, quepa llegar a una conclusión semejante (Mejía, 2016: 149 y ss.); no obstante, esta vía directa supondría que la Corte excediese su mandato expreso, que limita su competencia a la protección de los derechos civiles y políticos, y al excederse estaría comprometiendo una legitimidad que le ha costado mucho ganar. Por eso, la vía indirecta, la que supone garantizar el mínimo vital a través de la invocación de derechos civiles como el de la integridad personal, puede ser más prometedora y más eficaz (Ferrero, 2016: 1005).

Pues bien, creo que el «argumento hobbesiano» a favor de la garantía del mínimo vital (esto es, que toda comunidad política ha de asegurarlo a todos sus ciudadanos, como condición necesaria de cualquier pretensión de legitimidad, por mínima que esta sea) puede aplicarse sin dificultades al campo del ius post bellum. Si el ius post bellum ha de servir para garantizar una paz dotada de un cierto nivel de justicia y de estabilidad, ha de incluir en su contenido los mecanismos que articulen la garantía de la satisfacción de ciertas necesidades básicas, llámese derecho al mínimo vital o como se quiera, que, desde luego, habría de incluir esa disposición universal de niveles mínimos (o decentes) de agua, alimentación y alojamiento (y seguramente de educación y sanidad, puesto que la idea de la vida mínimamente digna no parece que sea concebible sin ellos). Las referencias contenidas en las sentencias citadas a la dignidad, o al mínimo innegociable, o a las condiciones necesarias para el ejercicio de todos los demás derechos, remiten al fundamento último de lo político, que es el aseguramiento de una vida decente para todos los miembros de la comunidad: una vida que sea preferible a la que podemos figurarnos en un imaginario estado de naturaleza o en un no tan imaginario estado de guerra como aquel que han tenido que soportar aquellos a los que se dirige el ius post bellum. Por supuesto, y así lo muestra la diversa procedencia de esas decisiones judiciales, la garantía del mínimo vital es exigible en cualesquiera circunstancias y 
no ha de asociarse en particular a una situación posbélica. Sin embargo, de lo que se trata aquí es de hacer ver que ese mínimo también ha de ser garantizado desde el momento en que se inicia la reconstrucción de una comunidad política que ha pasado por el trauma de la guerra, porque sin el disfrute de esas condiciones mínimas el resultado de esa reconstrucción no será realmente pacifico, ni estable, ni legítimo.

Hay quienes, en esta línea, han propuesto el reconocimiento de algunos derechos económicos y sociales (en particular, el derecho a la tierra, a la vivienda y a la propiedad) como parte del ius post bellum, encontrando apoyo normativo en el art. 11 del Pacto Internacional de Derechos Económicos Sociales y Culturales, de 1966, que establece el derecho de toda persona "a un nivel de vida adecuado", incluyendo "alimentación, vestido y vivienda» (Calvet y Díaz Anabitarte, 2018). La base de una propuesta como esta se halla o bien en la validez intrínseca de los derechos económicos y sociales (apoyada por su reconocimiento internacional) o bien en la tesis de la interdependencia de los derechos (Gready y Robins, 2014: 346), según la cual, y a los efectos que ahora interesan, la efectividad de los derechos civiles y políticos requiere del reconocimiento de los derechos económicos y sociales.

La propuesta del derecho al mínimo vital cabe vincularla con esta línea de argumentación, pero muestra dos ventajas específicas: una es que se trata de una propuesta más modesta en sus contenidos (y, por tanto, más fácil de asumir); la otra es que el derecho al mínimo vital no ha de ser considerado como un derecho «social», sino, de acuerdo con la jurisprudencia que viene de ser citada, como un derecho integrado en otros derechos civiles, sea el derecho a la vida, el derecho a la integridad, o sea la idea misma de dignidad. Esta distinta calificación del derecho (como derecho civil y no como derecho social) es una ventaja por dos motivos: primero, porque los derechos civiles presentan un consenso social y político y un reconocimiento jurídico mucho mayores que los derechos sociales; segundo, porque la tesis de la indivisibilidad no deja de ser una tesis problemática, al menos si la entendemos en sentido fuerte, que sería el sentido que permitiría justificar los derechos sociales con base en los derechos civiles (Nickel, 2008).

No ha de verse aquí escepticismo alguno sobre la fuerza de las razones que justifican la inclusión de los derechos sociales en el catálogo de los derechos humanos o fundamentales (de hecho, estoy convencido de que esas razones son tan fuertes como las que justifican la inclusión del resto de los derechos de ese catálogo). Lo que ha de verse es, más bien, una opción pragmática: a la hora de generar consenso sobre ciertos contenidos sustantivos de un ius post bellum formulado por la vía del derecho internacional (que requiere un acuerdo entre Gobiernos de signo muy diverso), la vía del mínimo vital parece 
más transitable que la vía de los derechos sociales. En todo caso, este reconocimiento no supondría obstáculo alguno a un hipotético y ulterior reconocimiento de contenidos adicionales de carácter económico y social. Al contrario, constituirá una razón para apoyarlo. Por el momento, baste con concluir que la justificación de la garantía del mínimo vital como parte integrante del ius post bellum no requiere siquiera de la invocación de ninguna concepción avanzada de los derechos humanos. Vale con el mucho más modesto, pero poderoso, argumento hobbesiano.

\section{Bibliografía}

Bass, G. J. (2004). Jus Post Bellum. Philosophy and Public Affairs, 32, 384-412. Disponible en: https://doi.org/10.1111/j.1088-4963.2004.00019.x.

Bobbio, N. (1985). Estudios de historia de la filosofia: de Hobbes a Gramsci. Madrid: Debate.

Calvet Martínez, E. y Díaz Anabitarte, A. (2018). The right to land, housing and property. En C. Stahn et al. (eds.). Jus Post Bellum and the Justice of Peace. Oxford: Oxford University Press (en prensa).

Champeil-Desplats, V. (2012). La justiciabilité des droits sociaux en Amérique Latine. En D. Roman (dir.). La justiciabilité des droits sociaux: vecteurs et résistances (pp. 223-235). Paris : Pedone.

De Brabandere, E. (2014). The Concept of Jus Post Bellum in International Law. En C. Stahn et al. (eds.). Jus Post Bellum: Mapping the Normative Foundations (pp. 123-141). Oxford: Oxford University Press. Disponible en: https://doi.org/10.1093/acprof:oso/9780199685899.003.0008.

Fercot, C. (2012). Le juge et le droit au minimum. Les ambigüites du droit a des conditions minimales d'existence en droit comparé. En D. Roman (dir.). La justiciabilité des droits sociaux: vecteurs et résistances (pp. 49-65). Paris: Pedone.

Fernández, E. (1987). La obediencia al derecho. Madrid: Civitas.

Ferrero, J. (2016). État des lieux de la justiciabilité des droits économiques, sociaux et culturels dans le système interaméricain. Revue trimestrielle des droits de l'homme, 108, 983-1005.

García Manrique, R. (2008). No hay guerras justas. En I. Campoy et al. (eds.). Desafios actuales a los derechos humanos: reflexiones sobre el derecho a la paz (pp. 113-145). Madrid: Universidad Carlos III, Dykinson.

Gready, P. y Robbins, S. (2014). From Transitional to Transformative Justice: A New Agenda for Practice. The International Journal of Transitional Justice, 8, 339-361. Disponible en: https://doi.org/10.1093/ijtj/iju013.

Habermas, J. (1998). Facticidad y validez. Sobre el derecho y el estado democrático de derecho en términos de teoría del discurso. Madrid: Trotta.

Hume, D. (1983 [1751]). An Enquiry Concerning the Principles of Morals (ed. J. B. Schneewind). Indianapolis: Hackett.

Hobbes, T. (1993 [1642]). El ciudadano. Madrid: Debate, CSIC.

- (1999 [1651]). Leviatán o la materia, forma y poder de un estado eclesiástico y civil. Madrid: Alianza. 
Iverson, J. (2014). Contrasting the Normative and Historical Foundations of Transitional Justice and Jus Post Bellum. En C. Stahn et al. (eds.). Jus Post Bellum: Mapping the Normative Foundations (pp. 80-101). Oxford: Oxford University Press.

Kleffner, J. K. (2008). From here to there... and the law in the middle. En C. Stahn y J. K. Kleffner (eds.). Jus Post Bellum. Towards a Law of Transition from Conflict to Peace (pp. 1-8). La Haya: Asser Press.

Locke, J. (2010 [1690]). Segundo Tratado sobre el Gobierno Civil. Madrid: Tecnos.

López Guerra, L. (2015). Crisis económica y derechos humanos: una nota de jurisprudencia. Teoria y Realidad Constitucional, 36, 399-414. Disponible en: https://doi.org/10.5944/ trc.36.2015.16066.

Meinecke, F. (1983). La idea de la razón de Estado en la Edad Moderna. Madrid: Centro de Estudios Constitucionales.

Mejía Rivera, J. A. (2016). Los derechos económicos, sociales y culturales a la luz del sistema interamericano de derechos humanos. En L. E. Ríos Vega e I. Spigno (eds.). Estudios de casos lideres interamericanos y europeos (pp. 127-158). México: Tirant lo Blanch.

Mestre, R. (2016). La protección de los derechos sociales por el Tribunal Europeo de Derechos Humanos. Cuadernos Electrónicos de Filosofía del Derecho, 33. Disponible en: https:// doi.org/10.7203/CEFD.33.8249.

Murphy, M. C. (1995). Was Hobbes a Legal Positivist? Ethics, 105, 846-873. Disponible en: https://doi.org/10.1086/293755.

Nagel, T. (1972). War and Massacre. Philosophy and Public Affairs, 1, 123-144.

Neumann, F. (1986). The Rule of Law. Political Theory and the Legal System in Modern Society. Leamington Spa: Berg.

Nickel, J. W. (2008). Rethinking Indivisibility: Towards A Theory of Supporting Relations between Human Rights. Human Rights Quarterly, 30, 984-1001. Disponible en: https:// doi.org/10.1353/hrq.0.0046.

Nivard, C. (2012). La justiciabilité des droits sociax. Étude du droit conventionnel européen. Bruxelles: Bruylant.

Orend, B. (2000). Jus Post Bellum. Journal of Social Philosophy, 31, 117-137. Disponible en: https://doi.org/10.1111/0047-2786.00034.

- (2008). Jus Post Bellum: a Just War Theory Perspective. En C. Stahn y J. K. Kleffner (eds.). Jus Post Bellum. Towards a Law of Transition from Conflict to Peace (pp. 31-52). La Haya: Asser Press.

Österdahl, I. (2012). Just War, Just Peace and the Jus Post Bellum. Nordic Journal of International Law, 81, 271-294. Disponible en: https://doi.org/10.1163/15718107-08103003.

Pugh, M (2008). Challenges of Post-Conflict Intercession: Three Issues in International Politics. En C. Stahn y J. K. Kleffner (eds.). Jus Post Bellum. Towards a Law of Transition from Conflict to Peace (pp. 115-130). La Haya: Asser Press.

Rawls, J. (1973). A Theory of Justice. Oxford: Oxford University Press. (2001). El derecho de gentes. Barcelona: Paidós.

Ruiz Miguel, A. (1988). La justicia de la guerra y de la paz. Madrid: Centro de Estudios Constitucionales. 
Sharma, S. K. (2008). Reconsidering the Jus ad Bellum/Jus in Bello Distinction. En C. Stahn y J. K. Kleffner (eds.). Jus Post Bellum. Towards a Law of Transition from Conflict to Peace (pp. 9-30). La Haya: Asser Press.

Stahn, C. (2007a). Jus ad bellum, jus in bello... jus post bellum? Rethinking the Conception of Law of Armed Force. The European Journal of International Law, 17, 921-943. Disponible en: https://doi.org/10.1093/ejil/chl037.

- (2007b). Jus Post Bellum: Mapping the Discipline(s). American University International Law Review, 23, 311-347.

- (2008). The Future of Jus Post Bellum. En C. Stahn y J. K. Kleffner (eds.). Jus Post Bellum. Towards a Law of Transition from Conflict to Peace (pp. 231-237). La Haya: Asser Press. Disponible en: https://doi.org/10.1007/978-90-6704-719-7.

Tuck, R. (1989). Hobbes. Oxford: Oxford University Press.

Walzer, M. (1977). Just and Injust Wars. A Moral Argument with Historical Illustrations. New York: Basic Books.

Warrender, H. (1957). The Political Philosophy of Hobbes. His Theory of Obligation. Oxford: Clarendon Press.

Wilde, R. (2008). Are Human Rights Norms Part of the Ius Post Bellum, and Shoud They Be? En C. Stahn y J. K. Kleffner (eds.). Jus Post Bellum. Towards a Law of Transition from Conflict to Peace (pp. 163-186). La Haya: Asser Press. 